\title{
A case study examining backchannels in conversations between Japanese-British dyads
}

\author{
PINO CUTRONE
}

\section{Abstract}

Listener responses (called backchannels) and their effect on intercultural communication were investigated in eight dyadic conversations in English between Japanese and British participants. The findings of this study revealed several differences in the way each culture used backchannels: the Japanese participants used slightly more backchannels per interlocutor word, the British participants displayed greater variability in the types of backchannels they used, and there were several differences in the lexical items making up these backchannels. Japanese participants sent noticeably more backchannels in three discourse contexts: at or directly after a pause, directly after a primary speaker's nonverbal gesture, and directly after a tag question or an utterance ending with the lexical items 'ya know'. This study found evidence supporting the hypothesis that backchannel conventions, which are not shared between cultures, contribute to negative perceptions and stereotyping. The findings of this study support the conclusion that backchannels warrant more attention in EFL classes in Japan.

\section{Introduction}

In my seven years living and teaching in Japan, I have noticed that the listening behaviour of Japanese EFL speakers differs somewhat from that of native English speakers. For instance, I have noticed that Japanese EFL speakers are much more active listeners in terms of frequency of listener responses (hereafter referred to as backchannels). These observations are consistent with the findings of Maynard (1997), White (1989), and Clancy et al. (1996). Further, while not mentioned in the research, I have also noticed that native English speakers generally used greater exuberance and variability in their backchannels. Lastly, and perhaps having the greatest impact on communication, I have observed that Japanese EFL speakers sometimes use backchannels in ways which may 
seem unconventional in English. This includes saying 'yeah', 'uhuh' and/ or nodding in situations when they do not understand or do not agree with what their interlocutor is saying.

Sometimes, these differences can result in misunderstandings and miscommunications in intercultural communication. In this paper, intercultural communication (IC) will refer broadly to the interactions between people of different nations that do not share the same linguistic or cultural background (Lustig and Koester 1993: 61). In their analyses of intercultural encounters involving Japanese EFL speakers, Locastro (1987), Maynard (1997), and White (1989) have noted that Japanese EFL speakers send backchannels frequently out of politeness (i. e. as a way to show they are listening attentively, and allow their interlocutor to continue speaking). However as Lebra (1976) and Mizutani (1982) have hypothesized, native English speakers may take such frequent interjections as a sign of the listener's impatience and demand for a quick completion of the statement. Further, some native English speakers may perceive their interlocutor's frequent backchannels as a sign that they do not want to speak. In such cases, some native English speakers may feel less inclined to engage in conversations with them.

Another area, which may be a source for potential misunderstanding in intercultural communication, involves the degree of exuberance, and the variability in the types of backchannels sent. Research has shown that Japanese are inclined to taciturn behaviour, and thus exuberant and diverse listening reactions may not be congruent with their nature (Zimbardo 1977). Alternatively, some native English speakers may interpret what are often regular low-key listener responses as being signs of indifference to what they are saying.

In considering instances where Japanese EFL speakers send backchannels when they do not understand or agree with their interlocutor, it is plain to see how misunderstandings and confusion can occur. Sometimes these misunderstandings can have dire consequences, as was the case in the Hitachi-Mitsubishi trial (The Japan Times 1983:2). One of the defendants in the case, Mr. Ishida of Mitsubishi, claimed that he had not agreed with the FBI undercover agents when they told him he had to steal some information/documents. His defense counselor argued that Mr. Ishida's responses of 'yeah' and 'uhuh' were not to show agreement, but rather to indicate he was listening and to allow the other person to continue.

In this study of backchannels and their effect on intercultural communication, I examine intercultural dyadic conversations in English between Japanese and British participants. I believe I am addressing an area of EFL in Japan that is in much need of research. Considering the potential misunderstandings outlined above, I believe a more extensive 
examination of how Japanese EFL speakers use backchannels is justified and perhaps long overdue. Despite their integral role in communication and the fact that their uses may differ between cultures, backchannels are largely neglected in EFL classes and textbooks in Japan (Capper 2000; Okushi 1990). With this in mind, the main purpose of this study is to determine whether backchannels warrant a higher priority in EFL teaching in Japan. The following research questions will be investigated to determine this.

(1) Will participants from each culture, Japanese and British, use backchannels differently in this study?

(2) If there are differences between the two cultures' backchannel behaviour, how will these differences affect communication?

To provide a clearer picture of this investigation, I break down these research questions into more specific questions illustrating the foci of each one. Research question one can be stated more specifically in the following queries:

(A) Will participants from each culture use backchannels differently in terms of frequency?

(B) Will participants from each culture differ in terms of the variability of types of backchannels used?

(C) Will the backchannel behaviour differ between cultures in terms of discourse contexts favouring backchannels? (The term discourse context favouring backchannels refers to the places or points identified in the primary speaker's speech where listeners frequently send backchannels)

Research question two can be stated more specifically in the following queries:

(D) Will backchannel conventions, which are not shared between the two cultures, contribute to negative perceptions in personality?

(E) Will backchannel conventions that are not shared between the two cultures cause misunderstandings and/or miscommunication?

If the findings of this study indicate that backchannels are used considerably differently across cultures, and these differences are found to have a negative effect on intercultural communication, then a conclusion advancing that backchannels should be given a higher priority in EFL teaching in Japan will be justified. 


\section{Literature review}

This literature review has two aims. First, it serves to provide a background for my study. Second, it serves to provide insights into Japanese backchannel behaviour. To achieve these aims, several key areas need to be addressed. First, the term backchannel needs to be clearly defined. Hence, I begin my literature review with a detailed description of what constitutes a backchannel. My description provides insights into the following three areas: (1) the identification of listener backchannel expressions, (2) the differentiation between a backchannel and a turn, and (3) the functions of backchannels in conversations. Subsequently, the research explores the workings of backchannels in Japanese and British cultures. The literature is presented on (4) backchannels compared across cultures (Japanese vs. Americans), (5) the effects of Japanese language and culture on Japanese backchannels, (6) and on backchannels in British English.

\subsection{Identifying listener backchannel expressions}

Most early research consisting of face-to-face interaction has tended to focus more on the speaker's role than on the listener's. Other than Fries (1952), Kendon (1967, 1977), Dittman and Llewellyn (1968), and Hall (1974), few studies have examined the turn of non-primary speakers in conversational interaction. Fries (1952: 49), in analyzing English conversations, was perhaps the first to group together 'those single free utterances ... that have as responses continued attention' including such utterances as Uh huh, Yeah, Mmm, I see, etc. Kendon (1967:23) called these utterances 'accompaniment signals'. Only recently has there been an increase in research activity concerning the behaviour of listeners in conversational interaction.

While there currently exist several terms to describe the utterances of non-primary speakers, the most widespread one is backchannel. The term, coined by Yngve (1970) in his pioneering research, is explained as follows:

When two people are engaged in conversation, they generally take turns ... In fact, both the person who has the turn and his partner are simultaneously engaged in both speaking and listening. This is because of the existence of what I call the backchannel, over which the person who has the turn receives short messages such as yes and $u h$-huh without relinquishing the turn. (Yngve 1970: 568)

While some researchers such as Oreström (1983) have followed Yngve's (1970) definition of backchannels in their studies, others have broadened 
it. Most notably, Duncan (1974) and Duncan and Fisk (1977) extend backchannels to include sentence completions, requests for clarification, brief statements, and non-verbal responses such as head nods and headshakes.

In the studies most closely resembling the one I am conducting (in terms of research design and in the use of Japanese participants), Maynard (1997) and White (1989) differed slightly in their identification of backchannels. Due to the fact that White (1989) was limited to audio recording in her conversation analysis, she was only able to examine the vocal backchannels of the participants in her study. Further, she reported on the five most frequently occurring backchannels in her study consisting of only paralinguistic ejaculations such as mmhm, yeah, uh-huh, $o h$, and $h m m$.

Maynard (1986, 1987, 1989, 1990, 1997), on the other hand, used a broader identification of backchannels as proposed by Duncan and Fiske (1977) in that she too includes sentence completions, requests for clarification, brief statements (longer than the common paralinguistic ejaculations mentioned above), and nonverbal items such as head nods and laughing. As I tend to agree with Maynard (1997) that brief utterances and nonverbal behaviour by the listener are indeed backchannels in that they serve as messages to the primary speaker, this broader definition of backchannels was used in the observations of the eight conversations in this study.

\subsection{Differentiating between a backchannel and a turn}

The most difficult aspect in identifying a backchannel seems to be in determining whether a particular behaviour constitutes a backchannel or a separate turn. According to Maynard (1986:1084), much of the confusion stems from distinguishing between 'having a turn' and 'having the floor' and can be attributed to self-contradictions in Yngve's (1970) definition. Although Yngve's (1970: 568) earlier definition of a backchannel is given in terms of 'not relinquishing a turn', he cites the following example as backchannel behaviour:

In one case, what looked like backchannel activity consisted of filling in needed personal background so that the person having the floor could continue. This went on for about thirty seconds and involved a number of sentences. It is interesting to note that this extensive backchannel activity was in turn provided with back-back channel activity of the 'uh-huh' variety. (Yngve 1970: 574) 
From this example, Yngve (1970:574) appears to be identifying backchannel behaviour on the basis of holding the floor, rather than having the turn.

Similarly, longer utterances such as 'You've started writing it then, your book' or 'I'll go if I can get the time off' in response to the primary speaker's talk can cause confusion because these utterances may allow the primary speaker to continue holding the floor, yet they appear to be speaking turns in themselves. Further, sometimes what starts as a backchannel may end up as a turn, if the primary speaker shows no willingness to continue speaking. To minimize confusion, and following the work of Maynard (1986, 1987, 1989, 1990, 1997), Tao and Thompson (1991) and White (1989), backchannels in this study will be identified in the context of the turn-taking system.

In their seminal work, Sacks et al. (1974) propose a model for the organization of turn-taking in conversations. Central to their discussion, Sacks et al. (1974) first coined the term 'transition relevant places' (TRPs) to identify moments at which exchange of turn is appropriate. TRPs are signalled by the conversation's participants to each other through various contextual cues such as silence or the end of a question (Sacks et al. 1974: 706). This analysis is relevant to this study because it advances that turn-taking is determined by the contextual cues used by the participants in the conversation. In later studies, Erickson (1979) and Schegloff (1982) demonstrated that listener responses are also determined by communication signals used by the participants in the conversation. Hence, TRPs have been helpful in assisting researchers to determine some of the discourse contexts where backchannels are often found (see Clancy et al. 1996; Maynard 1997; White 1989, etc.).

For the purpose of identifying backchannels in the turn-taking context, Markel's (1975) definition of a turn is especially useful. Markel (1975: 190) states, 'A speaking turn begins when one interlocutor starts solo talking. For every speaking turn there is a concurrent listening turn, which is the behaviour of one or more nontalking interlocutors present'. Markel (1975) advances that the only time that a change in speaking turn can take place is when the non-primary speaker begins solo speaking.

Solo speaking being some point or statement made which advances the conversation further, and does not include the backchannel utterances we have discussed above such as uhuh, mmm, and/or I see which seem only to serve in listening. In cases where there is simultaneous talk, the primary speaker continues to have the turn if the primary speaker solo speaks after the simultaneous talk. However, if the non-primary speaker begins solo speaking after the simultaneous talk, then a change of primary speaker turns would have occurred.

Lastly, pauses may contribute to confusion in differentiating between turns and backchannels. As has been shown in several studies, a pause 
often exists between the end of the previous turn and the beginning of the next turn (Markel 1975; Maynard 1986, 1997; Sacks et al. 1974, etc.). Pauses also often provide the opportunity for non-primary speakers to produce backchannels (Clancy et al. 1996; Maynard 1986, 1997; White 1989). Following Maynard (1986, 1997), this study takes the position that when a pause is observed during the primary speaker's turn (in the midst of solo speaking), that pause will be identified as internal to the current speaker's turn.

\subsection{Functions of backchannels}

Fries (1952), Oreström (1983), and Yngve (1970) believe backchannels are a means for the non-primary speaker to signal to the primary speaker that $\mathrm{s} / \mathrm{he}$ understands and agrees, and thus have a supportive function. From a different perspective, Erickson (1979) and Schegloff (1982) marked a critical point in the study of non-primary turns by looking at the interactional functions and contextual cues that affect conversation. In his analysis of interracial interviews, Erickson (1979) identified moments in which listeners are obliged to show more active listening responses than at other times while the speaker is speaking as listener response-relevant moments (LRRMs). Similarly, Schegloff (1982) advanced that turns in the turn-taking system should be analyzed in terms of their interactive functions. According to Schegloff (1982), backchannels serve as continuers. That is, they serve to pass an opportunity to produce a full turn, and thus have a regulative function.

The interactive function of backchannels advanced by Erickson (1979) and Schegloff (1982) has prompted further developments in this area. Jefferson (1984), using the term acknowledgment tokens, suggested that functional and sequential distinctions might exist between listener responses. This theme was followed by Goodwin (1986), who distinguished among the several types of non-primary responses by proposing an important interactional distinction between assessments and continuers. According to Goodwin (1986), assessments such as wow or great serve to evaluate the primary speaker's contribution, whereas continuers such as huh and $\mathrm{mmm}$ serve to signal to the primary speaker that s/he should continue talking.

More recently, Maynard (1986, 1987, 1989, 1990, 1997) has summarised the research in respect to the possible functions of backchannels. Maynard (1997:46) has identified the following six categories: (1) continuer, (2) understanding, (3) support and empathy, (4) agreement, (5) emotive, and (6) minor additions. The following explanations and hypothetical examples demonstrate these functions: 
(i) Allowing the speaker to continue: This is premised on the turn-taking system and specifically on the non-primary speaker forsaking the opportunity to take a primary speaking turn as proposed by Schegloff (1982).

(ii) Display of understanding of content: This is when the non-primary speaker feels it is necessary to show that $\mathrm{s} / \mathrm{he}$ understands the primary speaker. This can be seen in the following example:

(1) A: I'm going to that Italian restaurant near the station.

B: Yeah, I know.

A: I love their ...

(iii) Support and empathy toward the speaker's judgement: This occurs when the non-primary speaker responds with a show of support or empathy to an evaluative statement made by the primary speaker. For example:

(2) A: He did it again.

B: I find that weird.

A: Yeah

B: He'll have to apply ... .

This example could be interpreted as A feeling it necessary to provide support to B's evaluative statement I find that weird, hence A uttered the backchannel yeah.

(iv) Agreement: This is when the non-primary speaker reacts to a question or question-like utterance made by the primary speaker. This can be seen below:

(3) A: You mean, you heard already.

B: (Head Nod)

C.: Who told ...

This example shows B reacting with the backchannel 'head nod' in agreement to A's question like statement.

(v) Strong emotional response: These are when the non-primary speaker responds emphatically to a statement made by the primary speaker. These are found in the forms of laughs and exclamatory statements.

(vi) Minor addition, such as correction, or request for information: These occur in such instances as when the non-primary speaker corrects something the primary speaker has just uttered, or when the nonprimary speaker needs clarification (really is a common backchannel in this situation), or when the non-primary speaker attempts to add a word in completing the utterance the primary speaker has just made. 
Ultimately, it is necessary to point out that all of the above-mentioned functions of backchannels can come under a more general category of interactional processes, what Sacks et al. (1974) call recipient design. According to Sacks et al. (1974) recipient design refers to the efforts made by the participants in a conversation to adhere to one another's speaking turns. In other words, backchannels would seem to serve the all important function of helping conversations run more smoothly.

\subsection{Backchannels across cultures: Japanese vs Americans}

Addressing the main issue of this project, it is important to consider that the definitions and functions of backchannels stated above may vary according to culture. Several studies on intercultural communication focusing on interactional management aspects are available (see Erickson 1979; Hall 1974; Phillips 1976; Tannen 1984). More specific to this study, I examine research which investigates Japanese people's backchannel behaviour compared to that of native English speakers.

Two linguists in particular, Maynard (1997, 1990, 1989, 1987, 1986) and White (1989), have made significant contributions in this area. First, upon analyzing the data produced by the intercultural conversations in Maynard (1997) and comparing it to the results obtained by the contrastive analysis used in Maynard (1986, 1990), Maynard (1997) concluded that both the Japanese and the American participants' backchannel behaviour in the intercultural conversations were similar to that within their own cultural context. Maynard (1997) again found that the Japanese participants used far more backchannels than did the Americans. The Japanese participants provided backchannels every 4.5 seconds of their interlocutor's primary speaking turn, while the American participants provided backchannels every 19.25 seconds. Additionally, the Japanese participants' backchannels consisted mainly of brief utterances and did not vary considerably, while the American participants displayed greater variability in the types of backchannels they sent.

In the intercultural dyadic conversations in Maynard (1997), grammatical completion (especially in instances followed by a pause) again proved the most frequent discourse context of the American participants' backchannels, while the discourse contexts of the Japanese participants' backchannels varied considerably. The discourse contexts favouring the Japanese participants' backchannels again included pauses internal to the primary speaker's turn and cues (such as direct eye contact and tag questions) given by the primary speaker that some reaction is necessary. Further, the Japanese participants often employed backchannels which co-occurred with the primary speaker's speech creating simultaneous talk, while the Americans did not. This finding highlights one of the 
rationales for my study as it reveals a source for potential misunderstandings in communication between these two cultures. Native English speakers may take such interjections during their speaking turn as interruptions and as a sign of the listener's impatience.

In her study, which analyzes the effects of backchannels on intercultural communication, White (1989) examines an area of conversational analysis which has received little research attention. The findings in White's (1989) study answer two questions that are relevant to this study: (1) What are the differences in the use of Japanese and American backchannels? and (2) Do these differences contribute to negative perceptions and stereotypes across cultures? Regarding the first question, White's (1989) findings are consistent with those in Maynard $(1986,1990)$ in that the Japanese participants in her study also used backchannels far more frequently than the Americans (approximately 3:1) in intracultural dyads. In the intercultural dyads, it is interesting to note that the American participants altered their listening style in the directions of their nonnative interlocutors, while the Japanese listening style remained unchanged. Japanese still used more backchannels in intercultural conversations than Americans but the difference was far less (from 3:1 to 1.5:1). With regard to discourse contexts, White (1989) did not go into great detail here, although she did identify clause boundaries and pauses as primary discourse contexts favouring backchannels in both English and Japanese.

Regarding the second question, White (1989) found no evidence supporting the assertion that backchanneling conventions that are not shared between Japanese and Americans contribute to negative perceptions and stereotypes. This result is of great significance to my study because it contrasts with my own observations. As I mentioned previously, I believe that the different way Japanese speakers of English use backchannels to native speakers of English in intercultural conversations sometimes causes miscommunication and/or negative perceptions by the native speaker of English.

Several other studies examining Japanese-American intercultural communications such as Mizutani (1983), Miller (1988), and Yamada (1990) also offer insights which are consistent with the findings of Maynard (1986, 1989, 1990) and White (1989). However, as Maynard (1997) points out, these studies may be of limited value to researchers due to methodological shortcomings. For example, Mizutani (1983) tends to draw conclusions based on anecdotal evidence without presenting an actual analysis of intercultural discourse. And although Miller (1988) and Yamada (1990) do include analyses of intercultural discourse, they fail to convincingly control for sociolinguistic variables such as gender, 
age, social status, social context, and purpose of communication. In effect, interculturalness becomes only one of the many factors influencing the discourse created.

\subsection{The effects of language and culture on Japanese backchannels}

In an effort to explain the greater frequency of Japanese backchannels as compared to other cultures, some researchers have pointed towards Japanese culture (Locastro 1987; 1999; Maynard 1997; Kenna and Lacy 1994; and White 1989). Much has been written about the Japanese communication style, and their tendency to need to keep conversations harmonious and avoid confrontations (see Barnlund 1974; Hill 1990; Loveday 1982). This concept is referred to as $w a$ or omoiyari in Japanese culture, and according to Matsumoto and Boye Lafayette (2000: 193), it is one of the key concepts in understanding Japanese people. Several linguists such as Kenna and Lacy (1994), Locastro (1987, 1999), Maynard (1997), and White (1989) contend that Japanese use backchannelling behaviour, or aizuchi as it is referred to in Japanese, as a way to maintain harmony in conversations. According to Locastro (1987: 103), aizuchi is part of the Japanese conversational routine and to not use it enough would be impolite to one's conversational partner.

Taking a linguistic perspective, Maynard (1989, 1997), White (1989), and Miller (1988) suggest that Japanese use more backchannels than English speakers because the syntactic structure inherent in Japanese provides more backchannel opportunities. As I have discussed in the previous section, Japanese backchannels often occur in pauses in the talk, and particularly in pauses marked with linguistic devices such as phrase/clause final particles in Japanese or tag questions in English. In comparing the Japanese language to English, several linguists including Clancy (1982), Clancy et al. (1996), Maynard (1987, 1989), White (1989), and Yamada (1992) agree that Japanese talk tends to be broken up into smaller units bounded by more pauses than English. Hence, it would not be a great leap to assume that if there are more pauses in Japanese, there are more opportunities for backchannels.

Moreover, it is sometimes suggested that backchannel cues such as phrase/clause final particles in Japanese and tag questions in English operate similarly. Despite the fact that both structures are often followed by pauses, and both structures are sending additional hints or messages to the listener, this does not seem to be an accurate assessment. Tag questions in English are severely restricted in that they only occur at the end of sentences, whereas particles in Japanese can be placed within sentential boundaries. Ergo, the flexibility which particles in Japanese 
have seems to provide an additional discourse context for backchannels, which is not existent in English.

The structurally driven approach described above is consistent with the longstanding Sapir-Whorf hypothesis, which stipulates that the structure of a language determines how its speakers view the world (Sapir 1929). In contrast, Locastro (1999) proposes that a functional analysis may lead to more useful insights. Locastro (1999:379) argues that 'language behaviour is primarily the major means to communicate with others and would presumably develop over time to facilitate the playing out of that need'. In other words, she adopts a Vygotskian (1962) perspective in that she proposes that language is determined by the speakers' culture and environment.

Locastro's (1999) interpretation, which prioritizes sociocultural and cognitive pressures on the language code, has received some support regarding Japanese backchannels. For instance, Auer (1996) and Goodwin (1981) document how speaking turns are determined by the social interaction in a conversation including such cues as gaze at critical moments in the conversations and various components of prosody. Further, Clancy (1982: 72) suggests a cognitive explanation for the greater fragmentation of Japanese. She claims that Japanese talk may be divided into shorter units, followed by pauses, to limit the processing burden on the listener. Apparently, this would enable the listener more opportunities to provide the backchannels characteristic of Japanese talk.

\subsection{A look at the backchannel behaviour of British people}

Much of the early research studying backchannel behaviour was conducted by Americans and focused on American English (e.g. Duncan 1974; Fries 1952; Kendon 1967; Schegloff 1982; Yngve 1970). As this study uses British participants, it is necessary to provide some background on the British use of backchannels. One of the more detailed studies investigating the British use of backchannels was Oreström's (1983) analysis of ten conversations from the London-Lund corpus. While his focus of the prosodic features of backchannels is an area I do not examine extensively in this paper, there are other insights offered by his study, which are relevant here. For instance, Oreström (1983:122) identifies the most commonly used backchannels in his analysis as $m$ (50 percent), yes (34 percent), yeah (4 percent), $\mathrm{mhm}$ ( 4 percent), no (3 percent), and a smattering of other words and phrases such as good, quite, and ahah. Oreström's (1983) analysis of British backchannels is important because it provides researchers with a basis from which to begin comparing British backchannel behaviour to that of other cultures. 
In a study comparing backchannels in British and American English, Tottie (1990) found that Britons and Americans tend to use different types of backchannels. The leading backchannels in the American conversation Tottie (1990) analyzed included yeah (40 percent), $\mathrm{mhm}$ (34 percent), $\mathrm{hm}$ (11 percent), right (4 percent), and unhhunh/uhuh (4 percent); while the most frequently used backchannels in the two British conversations Tottie (1990) analyzed included yes (44 percent), $m$ (36 percent), no (36 percent), and yeah (4 percent). Tottie (1990) also found differences in the quantity of backchannels used in American and British conversations. In the American conversation, there were sixteen backchannels per minute, compared with just five per minute in the British conversations. In light of these results, one may speculate that intercultural conversations in English between Britons and Japanese people may contain a larger gap in backchannels than the 3:1 average that exists between Japanese people and Americans.

\section{Methodology}

As the research questions were complex and multifaceted in nature, various methodological frameworks were considered in conducting this study. Ultimately, it was decided that the most reliable and valid approach in collecting data involved a combination of the three methods being considered: observations, questionnaires, and interviews. The following sections of part two will outline the process by which participants were selected, the procedures for collecting data, and the methods used for analyzing data.

\subsection{Participant selection}

The participants in this study consisted of eight L1 British English speakers from England and eight L2 Japanese-English speakers born and raised in Japan. Of the eight participants of each nationality, four were male and four were female. At the time of the study, fourteen of the participants resided in Okayama Prefecture in Japan, while two were visiting from England for approximately a month. The Japanese participants consisted of two teachers, a sales clerk, a sales manager, a business owner, a baker, a doctor, and one unemployed person (who was set to begin a full time engineering job upon graduating university in April 2002). The British participants included six EFL teachers and two university students who were part-time sales clerks. Thirteen of the participants were university graduates while the other three were attending university at the time of the study. The participants ranged in age from twenty to forty-one. 
When I was considering potential participants for my study, certain requirements first needed to be met. First, it was required that the Japanese participant be able to comfortably maintain a conversation in English with a native speaker of English. Second, in selecting my native English speaker participants, it was required that they all speak British English. To ensure that they were native speakers of British English with minimal foreign culture experience, I chose only those whose parents were born in England. Another requirement of my British participants was that they had lived in Japan for less than a year. A short period of residence in Japan was thought to be important because the longer the contact with members of the other culture, the greater the possibility of changes in backchannel use and interpretations (Locastro 1987: 103; White 1989:61). However, due to the fact that I was limited in my choices of participants for my study, one of my participants had lived in Japan for eight years and was fluent in Japanese. Accordingly, it will be interesting to see if his use and perceptions of backchannels differ from the other British participants.

The sociolinguistic characteristics of each participant also played a part in the participant selection process. As part of my study involved observing intercultural dyadic conversations, every effort was made to create intercultural dyads in which both participants contained common sociolinguistic characteristics such as gender, age, and social status. Hence, for the most part, my study was able to control for these variables. All dyads were paired according to gender, and in all cases but one, the ages of the participants in each dyad were within three years of each other. However, due to the practical constraints I mentioned above, one of the dyads consisted of a forty-one year-old Japanese man paired with a twenty-seven year-old British man. Likewise, there is some variability between the occupations of the participants in each dyad. The dyads consisted of the pairs shown below in Table 1 .

Lastly, I was also concerned with the extent to which the participants in each dyad knew each other. On the one hand, it would be beneficial if participants were friends because it would promote the casual conversational register I was seeking. On the other hand, nonfamiliarity between the participants in each dyad would ensure that perceptions would

Table 1. Dyads according to culture, gender, and occupation.

\begin{tabular}{ll}
\hline FEMALE & MALE \\
\hline (1) sales clerk - sales clerk (student) & (5) business owner - EFL teacher \\
(2) teacher - sales clerk (student) & (6) doctor - EFL teacher \\
(3) baker - EFL teacher & (7) doctor - EFL teacher \\
(4) sales manager - EFL teacher & (8) unemployed (student) - EFL teacher \\
\hline
\end{tabular}

(Japanese participant's occupation is shown first in each case) 
not be influenced by each interactant's prior knowledge of the other's personality traits. Taking both arguments into account, and considering the participants who were available to me, I allowed for some participant contact prior to the study, but made every effort to pair dyads together who were less familiar with each other. In cases where the members of the dyads were complete strangers (4 cases), I allowed them to get acquainted for an hour or so prior to being videotaped.

\subsection{Procedures in collecting data}

\section{i) Observations}

I employed three methods of collecting data for this study consisting of observations, questionnaires, and interviews. The first of these three methods, observations, involved the videotaping of eight intercultural dyadic conversations in English between L2 Japanese and L1 British participants. The conversations were conducted in various locations and at various times according to the convenience of the participants. All locations were small, quiet, and comfortably furnished. Video recording equipment consisted of a Sony digital video camera, which was placed unobtrusively in the corner of each room. At the time of the videotaping, only the participants were present in the room when the conversation was taking place.

Each of the eight dyads was instructed to talk as casually and as naturally as possible about anything they like for a period of nine minutes. Once nine minutes had elapsed, I re-entered the room and stopped the recording. Initially, in order to encourage equal participation in the conversations, I had planned to provide topics and prompts for the conversations, however, I discovered in two pilot conversations I conducted (with people not included in this study) that suggesting topics largely confused and even led the participants away from natural conversation.

A factor which may have influenced the conversations is what Labov (1972: 209) calls the observer's paradox. This refers to the fact that participants may have generated artificial behaviour because they were conscious that the conversations were being videotaped. In fact, at some early points in the conversations in this study, some participants looked towards the camera and made metamessage comments such as 'I guess we should start now' and 'I probably shouldn't say that in front of the camera'. As researchers such as Johnstone (2000:42) and Maynard (1986: 1086) have come to accept, these types of actions are generally predictable when participants are being videotaped.

To minimize the influence of being videotaped on the data, I categorically excluded the initial three minutes and the final three minutes of 
film from the eight videotaped conversations. Hence, I only used the middle three minutes of each conversation as data to be transcribed. It was thought that the participants would become less conscious of the camera as the conversation progressed, and it was felt that the middle part of the conversation would be the most natural as it avoids the awkwardness which often occurs at the beginning and end of conversations between people who do not know each other well.

\section{ii) Questionnaires}

The second method of data collection was through the distribution of a questionnaire. The questionnaire I used was a modified version of the one Hecht (1978) designed to measure conversational satisfaction and personality perception (also used in White 1989). The questionnaire used in my study consisted of a fifteen-item inventory. Questions were closedended, consisting of statements on a Likert-scale ranging from one to seven. I modified the questionnaire from Hecht's (1978) original and the one White (1989) used because my pilot studies revealed that some vocabulary and some of the statements, which contained double negatives, confused participants.

The questionnaires were given to each participant in the dyad directly after their videotaped conversation and were simultaneously completed in separate rooms. I asked participants privately to be as honest as possible in filling out the questionnaire, and reassured them that their identities would be concealed in all instances (pseudonyms are used in this paper). None of the participants took longer than ten minutes in completing the questionnaire.

\section{iii) Interviews}

The third method of data collection involved conducting oral interviews. The two members in each dyad were interviewed separately and in succession with the British participant first and the Japanese participant second. No one else was present at the time of the interview, as I asked the participant not being interviewed to wait in another room while the interview was being conducted. None of the interviews took longer than thirty minutes. The interviews consisted of me playing back a portion of the videotaped conversation and asking the participants a few questions pertaining to the listening behaviour displayed in the conversation. I took field notes and audio taped all interviews to refer to in my data analysis.

The interviews were semi-structured in that I had a general plan for the interviews, but did not enter with a predetermined set of questions as some of my questions were guided by the circumstances in the videotaped conversations and the responses of the interviewee. As suggested 
by Brown (2001:80), I sequenced my questions such that they began with general questions and gradually led to more specific and potentially sensitive questions in an effort to make participants feel more comfortable and thus provide more honest data. Upon asking a few general questions such as 'How was the conversation' and 'How did you feel about being in front of the camera?', I explained to each interviewee that my study was primarily examining the listener responses of the Japanese participant. I attempted to be cautious in my reactions to responses and in my wordings of questions so as not to lead the interviewees in any way. Open-ended and closed-ended questions were used in the interviews.

My main aim in my interviews with the British participants was to learn how they perceived their Japanese interlocutors' backchannels. A major part of the interview involved me playing back the videotape and asking the British interviewee to comment on the listening behaviour of their Japanese interlocutor. In instances which I had singled out for analysis (where some of the Japanese participants' backchannels occur), I stopped the videotape and asked specific questions such as 'What function do you think that head nod serves?', 'Do you think s/he understands what you are saying here?', and follow up questions such as 'Why do you think so?' I made a note of any data which I thought might be useful in my subsequent interview with the Japanese participant of the dyad.

In interviewing the Japanese participant, I had two main objectives. First, I wanted to learn as much as I possibly could about why Japanese EFL speakers use backchannels the way they do. Second, I wanted to determine if there were any misunderstandings or miscommunications caused by their use of backchannels in the videotaped conversations. I interviewed the British participant first because I thought that by hearing the British participant's insights prior to interviewing their Japanese interlocutor, I would, in interviewing the Japanese participant, be able to discover instances where the Japanese participants' backchannels may have been misunderstood in the conversation. Hence, a major part of my interview with the Japanese participants consisted of me asking them to comment on their own backchannel behaviour in the videotaped conversation.

In instances which I singled out for analysis (where some of the Japanese participants' backchannels occur), I stopped the videotape and asked specific questions such as 'What is the reason for saying yeah yeah here?', 'Do you understand what he/she is saying here?' and 'Do you agree with what s/he is saying here?' In the cases where the Japanese participant's backchannel explanation differed greatly with that of the British participant's interpretation, I asked potentially sensitive followup questions such as 'Why did you nod if you did not understand what 
s/he was saying here?' and 'Why did you say yeah if you disagreed with what s/he was saying?' In cases where the interviewee seemed uncomfortable in answering, I did not pursue that line of questioning further.

\subsection{Data analysis}

\section{i) Observations}

Due to the nature of this study and the multiple methods used, the amount of data collected was substantial. In analyzing my data, my first step was to transcribe the eight conversations according to the definition and conventions of backchannels, which I have described in the literature review. Similar to Maynard (1986, 1990, 1997), Tottie (1990) and White (1989), backchannels were investigated according to three criteria: frequency, variability, and discourse contexts. To show the frequencies of different types of backchannels (i. e., variability), I categorized the verbal backchannels in this study according to three types: simple, compound, and complex.

To illustrate this distinction, it is useful to first present Tottie's (1990) classification of backchannels and backchannel items, where the former could consist of one or more of the latter. For example, the sequence Yeah, I know can function as one backchannel but consist of three backchannel items. Similarly, in my categorization, a simple backchannel such as yeah is one which has only one backchannel item. A compound backchannel such as yeah yeah yeah is one in which one backchannel item exists but is repeated more than once. A complex backchannel such as yeah sure right consists of multiple and varied backchannel items. Accordingly, decisions had to be made as to when two or several simple backchannels occurring close to each other in the discourse made up one or several backchannels. My position was to regard two or several simple backchannel items as one backchannel if they were adjacent in time. I regarded them as separate backchannels if they were separated by several words or a long pause. To strengthen the internal reliability of my analysis, I transcribed the conversations with two of my colleagues. It was required that we reach a consensus on how the transcriptions were to be presented according to the conventions I have outlined above.

With regard to identifying the discourse contexts favouring backchannels in this study, my analysis explored the discourse contexts which were suggested in prior research in this area (see Clancy et al. 1996; Maynard 1997; White 1989). The discourse contexts that were examined in this study include the following:pauses, grammatical completion points, points in which both pauses and grammatical completion points 
occurred simultaneously, following primary speaker's nonverbal gestures such as a head nod, laugh, and/or smile, and following the lexical items ya know or a tag question.

\section{ii) Questionnaires}

The second phase of the data analysis process involved an examination of the questionnaires. My aims here were twofold. First, I wanted to discern generally how participants from each culture felt about one another after the conversations. I did this by calculating the means of each item in the questionnaire as they corresponded to each culture. Second and more specifically, I wanted to determine if there was any correlation between the frequency of the Japanese backchannels and the perceptions of the British interlocutors. To determine this, I conducted an analysis using the Pearson product-moment correlation coefficient. This is a numerical representation of the degree to which two sets of numbers are related (see Brown 2001:131 for an in-depth explanation of this procedure). Hence, my analysis measured the degree to which the number of Japanese backchannels in each conversation (one set of numbers) correlated with the British responses of each item on the questionnaire (the other set of numbers) from corresponding conversations.

\section{iii) Interviews}

The third and final phase of the data analysis process consisted of an examination of the data produced in the interviews. The texts of the interviews were transcribed verbatim, and then examined for emergent themes. These themes were based on two considerations: the various patterns found in the interviews, and in answer to questions pertaining to key concepts in this study. In describing the former, my analysis of the interview text involved synthesizing the data in such a way as to produce possible patterns, yet without misrepresenting or distorting the data. In describing the latter, my analysis of the interview text also focused on finding answers to questions which delve deeper into the reasons Japanese EFL speakers use backchannels the way they do, and how their backchannels are perceived by native speakers of English.

\section{Results}

Each of the three methods, observations, questionnaires, and interviews, served to answer different questions about backchannels as they are relevant to the Japanese EFL learner. The data gathered by the observation phase describes how Japanese and British participants used backchannels differently in terms of the frequency, variability, and discourse contexts favouring backchannels. The data obtained by the question- 
naires reveal how participants felt about each other after the conversations, and if the British perceptions were influenced by the frequency of the Japanese backchannels. The data produced by the interviews provide several insights, which are presented in three parts. First, I will explore the extent to which participants were affected by the observer's paradox, and I examine how participants changed their behaviour because they were speaking across cultures. Second, I report the results as they pertain to the functions of the Japanese participants' backchannels, and third, I describe how the British participants perceived the Japanese participants' backchannels.

\subsection{Frequency of backchannels}

In examining whether there was a difference in frequency of backchannels between the two cultures, the conversational data showed that the Japanese participants used more backchannels than the British participants, but not with as great a disparity as initially expected. Table 2 lists the observed frequency of backchannel occurrences as they pertain to each culture, and also shows the differences as they pertain to gender. The overall frequency count was 298 among Japanese speakers compared to 124 among British speakers. However, these figures do not accurately reflect the differences in frequency of backchannels between the two cultures because they do not account for the number of opportunities members from each culture had to send backchannels. A more accurate representation would take into account the ratio of backchannels per interlocutor's word. A word count for each culture revealed that the British participants used 1,985 words, while the Japanese participants used 887 words. Hence, a more accurate way to present these findings is to report that the Japanese participants provided a backchannel for every 7.1 of their interlocutor's words, whereas the British participants provided a backchannel for every 8.1 of their interlocutor's words.

The difference in terms of frequency between the two cultures was not statistically significant (a chi square test revealed that $\mathrm{p}>.05$ ). The results differ somewhat from the findings in White (1989) and Maynard (1997), who both found a greater difference in the frequency of backchannels between Japanese L2 English speakers and native speakers of English. This study found that the Japanese participants used more backchannels than the British participants by a ratio of 1.14:1 backchannels per interlocutor's word, whereas White (1989) found that the Japanese participants in her study provided more backchannels than the American participants by a ratio of 1.5:1 backchannels per interlocutor's word, and Maynard (1997) found that the Japanese participants provided backchannels every 4.5 seconds of their interlocutor's speaking turn compared to every 19.25 seconds for the American participants. 
Table 2. Differences in frequency of backchannels across cultures.

\begin{tabular}{|c|c|c|c|c|c|c|}
\hline \multirow[t]{2}{*}{ Conversations } & \multicolumn{2}{|c|}{ Total Backchannels } & \multicolumn{2}{|c|}{ Total Words } & \multicolumn{2}{|c|}{$\begin{array}{l}\text { Average number of } \\
\text { interlocutor's words } \\
\text { between backchannels }\end{array}$} \\
\hline & Japanese & British & Japanese & British & Japanese & British \\
\hline $\begin{array}{l}\text { Female } \\
1 \\
2 \\
3 \\
4 \\
\text { Female Total } \\
\text { Mean }\end{array}$ & $\begin{array}{r}48 \\
57 \\
27 \\
32 \\
164 \\
41\end{array}$ & $\begin{array}{c}9 \\
8 \\
5 \\
25 \\
47 \\
11.8\end{array}$ & $\begin{array}{c}70 \\
48 \\
77 \\
179 \\
374 \\
93.5\end{array}$ & $\begin{array}{c}271 \\
323 \\
281 \\
210 \\
1085 \\
271.3\end{array}$ & $\begin{array}{r}5.65 \\
5.67 \\
10.41 \\
6.56 \\
28.29 \\
7.1\end{array}$ & $\begin{array}{c}7.78 \\
8 \\
15.4 \\
7.16 \\
38.34 \\
9.6\end{array}$ \\
\hline $\begin{array}{l}\text { Male } \\
5 \\
6 \\
7 \\
8 \\
\text { Male Total } \\
\text { Mean }\end{array}$ & $\begin{array}{c}29 \\
31 \\
49 \\
25 \\
134 \\
33.5\end{array}$ & $\begin{array}{l}21 \\
27 \\
12 \\
17 \\
77 \\
19.3\end{array}$ & $\begin{array}{c}182 \\
155 \\
73 \\
103 \\
513 \\
128.3\end{array}$ & $\begin{array}{l}323 \\
156 \\
233 \\
188 \\
900 \\
225\end{array}$ & $\begin{array}{c}11.14 \\
5.03 \\
4.76 \\
7.52 \\
28.45 \\
7.1\end{array}$ & $\begin{array}{r}8.67 \\
5.74 \\
6.08 \\
6.06 \\
26.55 \\
6.6\end{array}$ \\
\hline $\begin{array}{l}\text { Overall Total } \\
\text { Overall Mean }\end{array}$ & $\begin{array}{l}298 \\
37.3\end{array}$ & $\begin{array}{l}124 \\
15.5\end{array}$ & $\begin{array}{l}887 \\
110.9\end{array}$ & $\begin{array}{l}1985 \\
248.1\end{array}$ & $\begin{array}{r}56.7 \\
7.1\end{array}$ & $\begin{array}{r}64.9 \\
8.1\end{array}$ \\
\hline
\end{tabular}

This study found that the male British participants produced more backchannels per interlocutor's word than the male Japanese participants (1:6.6 and 1:7.1 respectively). In comparison, the Japanese female participants produced more backchannels than did their British female interlocutors (1:7.1 and 1:9.6 respectively). Other studies involving Japanese L2 English speakers engaging in intercultural communication such as White (1989) and Maynard (1997) did not discuss the possibility that gender may be a factor affecting frequency of backchannels.

Several factors may have contributed to these results. First, regarding the more frequent use of backchannels by the male British participants, I speculate that the fact that one of the male British participants had lived in Japan considerably longer than the other participants may have played a role. That is, it is possible that his eight years residence in Japan may have altered his use of backchannels towards that of the host culture. However, when I asked him if he felt his backchannel behaviour had changed at all since he came to Japan, he responded that he was not consciously aware of any changes. Nonetheless, the fact that he sent backchannels more frequently than his interlocutor and that the differential (2.47 words) was the largest found in the male dyads certainly had an effect on the overall higher frequency of the male British backchannels. 
Another consideration is that the British participants may have altered their listening behaviour somewhat in an effort to assist their Japanese interlocutors who are less proficient in English. Several researchers have studied linguistic accommodations made by native speakers in intercultural settings. According to Ferguson (1975), Giles (1975), and Snow et al. (1981), native speakers make several forms of phonological, syntactic, and semantic adaptations when talking to a nonnative speaker in order to facilitate comprehension and allow the conversation to run more smoothly. As is evidenced by the great disparity in the total number of words spoken between the Japanese and British participants (887 to 1995 respectively), it can be argued that the British participants may have sent backchannels at a more frequent rate than usual to encourage their Japanese interlocutors to speak more. By the same token, as I will explore further in section six, it can also be argued that the Japanese may have sent backchannels frequently for the purpose of avoiding speaking.

\subsection{Variability of backchannels}

As shown below in Table 3, the British participants displayed somewhat more variability in the types of backchannels they used. The types of backchannels the British participants used were divided as follows: 25.8 percent simple accompanied by head nod(s), 19.4 percent simple, 12.9 percent complex, 12.9 percent multiple head nods, 9.7 percent isolated head nod, 4.8 percent complex accompanied by head nod(s), 4 percent compound accompanied by head nod(s), 3.2 percent laughter, 2.4 percent raised eyebrows, 2.4 percent compound, 1.6 percent smile, and 0.8 percent consisting of two or more nonverbal backchannels occurring simultaneously. In comparison, the types of backchannels the Japanese participants used were divided as follows: 39 percent simple accompanied by head nod(s), 16 percent isolated head nod, 13.4 percent simple, 9 percent multiple head nods, 0.7 percent compound accompanied by head nod(s), 7 percent complex accompanied by head nod(s), 4 percent complex, 2.3 percent laughter, 0.7 percent raised eyebrows, 0.7 percent compound, 0.3 percent smile, and 0.3 percent consisting of two or more nonverbal backchannels occurring simultaneously. The Japanese backchannels were marked by their more frequent use of head nod(s) occurring in all categories involving head nods except the 'multiple headnods' category. The findings that such a large portion of the Japanese backchannels ( 39 percent) in this study belong to one category (simple accompanied by head nod) reveals one of the areas where potential misunderstandings may occur. That is, native speakers of English may misunderstand this type of backchannel, which is constantly repeated, as a sign 
Table 3. Types of backchannels across cultures.

\begin{tabular}{|c|c|c|c|c|c|c|c|c|}
\hline \multirow{2}{*}{$\begin{array}{l}\text { Types of Back- } \\
\text { channels }\end{array}$} & \multicolumn{4}{|c|}{ Japanese Backchannels } & \multicolumn{4}{|c|}{ British Backchannels } \\
\hline & Fer & Male & Raw & percent & Female & Male & Raw & percent \\
\hline 1. Simple & 26 & 14 & 40 & 13.4 & 12 & 12 & 24 & 19.4 \\
\hline 2. Compound & 1 & 1 & 2 & 0.7 & 1 & 2 & 3 & 2.4 \\
\hline 3. Complex & 9 & 3 & 12 & 4 & 4 & 12 & 16 & 12.9 \\
\hline $\begin{array}{l}\text { 4. Simple accom- } \\
\text { panied by head } \\
\text { nod(s) }\end{array}$ & 54 & 61 & 115 & 39 & 9 & 23 & 32 & 25.8 \\
\hline $\begin{array}{l}\text { 5. Compound ac- } \\
\text { companied by } \\
\text { head nod(s) }\end{array}$ & 11 & 9 & 20 & 7 & 1 & 4 & 5 & 4 \\
\hline $\begin{array}{l}\text { 6. Complex accom- } \\
\text { panied by head } \\
\text { nod(s) }\end{array}$ & 12 & 10 & 22 & 7 & 0 & 6 & 6 & 4.8 \\
\hline $\begin{array}{l}\text { 7. Isolated head } \\
\text { nod }\end{array}$ & 26 & 23 & 49 & 16 & 6 & 6 & 12 & 9.7 \\
\hline $\begin{array}{l}\text { 8. Multiple head } \\
\text { nods }\end{array}$ & 19 & 8 & 27 & 9 & 9 & 7 & 16 & 12.9 \\
\hline 9. Smile & 1 & 0 & 1 & 0.3 & 1 & 1 & 2 & 1.6 \\
\hline 10. Laughter & 5 & 2 & 7 & 2.3 & 1 & 3 & 4 & 3.2 \\
\hline 11. Raised eyebrows & 0 & 2 & 2 & 0.7 & 3 & 0 & 3 & 2.4 \\
\hline $\begin{array}{l}\text { 12. Two or more } \\
\text { nonverbal back- } \\
\text { channels occur- } \\
\text { ring simultane- } \\
\text { ously }\end{array}$ & 0 & 1 & 1 & 0.3 & 0 & 1 & 1 & 0.8 \\
\hline
\end{tabular}

that the listener is not really interested in what s/he is saying, or that the listener is only pretending to understand.

I now explore how individual lexical items used in the aforementioned types differed according to each culture (see Table 4 below). The lexical item yeah was the most frequently used backchannel for both cultures. The Japanese participants used it 61 times, while the British participants used it 20 times. Other items, which were comparable, included $m$ (25 occurrences for Japanese, and 11 occurrences for British), uhum (13 occurrences for Japanese, and 10 occurrences for British), ah (11 occurrences for Japanese, and 8 occurrences for British), and uhuh (6 occurrences for Japanese, and 5 for British). Although the total number of backchannels used by each culture is indeed an important consideration for our earlier comparison, it is not included here, as it would not produce an accurate ratio of lexical items per backchannel because many of the verbal items have been used repeatedly within the same backchannel.

Some of the lexical items used as backchannels (or parts thereof) were specific to each culture. The lexical items specific to the Japanese partici- 
Table 4. Variability in lexical items used in backchannels across cultures.

\begin{tabular}{llrrrrrrrrrrrrr}
\hline & yeah & $(u)$ n oo & $m$ & ah & uhum & uhuh & no & yes & really & right & oh & yep & o $(k)$ \\
\hline Japanese & 61 & 59 & 19 & 25 & 11 & 13 & 6 & 6 & 3 & 2 & 2 & 4 & 0 & 0 \\
British & 20 & 0 & 2 & 11 & 8 & 10 & 5 & 4 & 0 & 0 & 7 & 8 & 3 & 13 \\
\hline
\end{tabular}

pants included $(u) n$ (59 occurrences for Japanese, and none for British), and oo (19 occurrences for Japanese, and 2 occurrences for British). In comparison, some of the items specific to British backchannels included ok or kay (13 occurrences for British participants, and none for Japanese), oh ( 8 occurrences for British, and 4 occurrences for Japanese), and right (7 occurrences for British, and 2 occurrences for Japanese). In summary, it is plain to see that there are several differences in the lexical items that each culture used as backchannels in this study.

\subsection{Discourse contexts favouring backchannels}

My next inquiry involves determining whether there are important differences between the two cultures in where the speakers choose to place backchannels within the primary speaker's turn. To best illustrate the discourse contexts favouring backchannels, the total number of occurrences of each potential discourse context was divided by the number of backchannels occurring in those contexts (see Table 5 below for raw scores and percentages of occurrences). Thus, considering the number of opportunities presented by each discourse context, I observed that the Japanese participants sent more backchannels per opportunity than British participants in three contexts: at or directly after a pause (1.3:1), directly after a primary speaker's nonverbal gesture (1.2:1), and directly after tag questions or ya know (1.9:1). A chi square test revealed these differences in frequencies not to be statistically significant (at $p>.05$ ).

Regarding the number of backchannels sent during the primary speaker's speech, the raw scores indicate that the Japanese participants sent backchannels far more frequently than the British participants (120 to 45 respectively).

However, it is difficult to compare these numbers with any certainty because the Japanese participants had a greater opportunity in this category because their British interlocutors spoke much more. Measuring the amount that each participant spoke in terms of quantifiable opportunities seems to best be reflected on the dichotomous scale:(1) during speech and (2) when there is a pause. However, this scale is not likely to 
Table 5. Discourse contexts of backchannels across cultures.

\begin{tabular}{|c|c|c|c|c|c|c|}
\hline \multirow{2}{*}{$\begin{array}{l}\text { Discourse Contexts } \\
\text { for Backchannels }\end{array}$} & \multicolumn{3}{|c|}{ Japanese Backchannels } & \multicolumn{3}{|c|}{ British Backchannels } \\
\hline & Total & $\begin{array}{l}\text { Oppor- } \\
\text { tunities }\end{array}$ & percent & Total & $\begin{array}{l}\text { Oppor- } \\
\text { tunities }\end{array}$ & percent \\
\hline 1. During primary speaker's talk & 120 & - & - & 45 & - & - \\
\hline 2. At or directly after a pause & 178 & 356 & 50.7 & 79 & 204 & 38.7 \\
\hline $\begin{array}{l}\text { 3. At or near a grammatical } \\
\text { completion point }\end{array}$ & 44 & 362 & 12.2 & 20 & 280 & 14 \\
\hline $\begin{array}{l}\text { 4. At or directly after a point in } \\
\text { which both a pause and gram- } \\
\text { matical completion point occur }\end{array}$ & 127 & 198 & 64.1 & 59 & 98 & 60.2 \\
\hline $\begin{array}{l}\text { 5. After a primary speaker's } \\
\text { nonverbal gesture }\end{array}$ & 20 & 25 & 80 & 17 & 25 & 68 \\
\hline 6. After tag questions or 'ya know' & 3 & 8 & 37.5 & 1 & 5 & 20 \\
\hline
\end{tabular}

provide a competent assessment of this phenomenon as it does not take into account the number of turns each person took, and the length of each person's turn. In the other two discourse contexts examined in this study, at or near a grammatical completion point, and at or directly after a point where a grammatical completion point and a pause occur simultaneously in the primary speaker's turn, the data did not reveal any marked difference between the uses of backchannels between the Japanese participants and the British participants.

The results in this study were similar to those in Maynard (1997). This study also found that the discourse contexts which the Japanese EFL speakers favoured for sending backchannels varied considerably, and that grammatical completion points, especially those coinciding with a pause, were common discourse contexts for the English native speakers' backchannels. However, unlike Maynard (1997), this study found that the British participants frequently sent backchannels after their interlocutors' nonverbal gesture(s).

\subsection{Examining participants' conversational satisfaction}

Overall, the results from the questionnaire (as shown in Table 6 below) were similar across cultures, and indicated that all participants generally had positive impressions from their conversations with their intercultural interlocutors. Two factors may have contributed to these ratings. First, the British participants may have been more tolerant of misinterpretations in the conversations because they attributed them to the fact that their Japanese interlocutors were less competent in English. Accord- 
Table 6. Participants' Conversational Satisfaction.

\begin{tabular}{lll}
\hline Items on Questionnaire & $\begin{array}{l}\text { Japanese } \\
\text { Mean }\end{array}$ & $\begin{array}{l}\text { British } \\
\text { Mean }\end{array}$ \\
\hline 1. S/he let me know I was communicating effectively. & 2.5 & 2.5 \\
2. I felt I was able to present myself fairly during the & 3.5 & 2.63 \\
conversation. & 2.38 & 2.44 \\
3. S/he showed me that s/he understood what I said. & 1.88 & 2.88 \\
4. S/he showed s/he listened attentively to what I said. & 1.75 & 3.25 \\
5. S/he expressed a lot of interest in what I had to say. & 2.38 & 2.88 \\
6. The conversation went smoothly. & 1.5 & 3.38 \\
7. S/he encouraged me to continue talking. & 5.25 & 5.63 \\
8. S/he seemed impatient. & 7 & 7 \\
9. S/he seemed cold and unfriendly. & 1.5 & 2.13 \\
10. S/he was polite. & 1.13 & 2.25 \\
11. S/he appeared warm and friendly. & 7 & 6.25 \\
12. S/he was impolite. & 1.38 & 2.25 \\
13. S/he was an attentive listener. & 1.75 & 2.5 \\
14. S/he appeared interested and concerned. & 6.88 & 6 \\
15. S/he interrupted me. & &
\end{tabular}

N.B. Scores are observed on a scale ranging from 1 (strongly agree) to 7 (strongly disagree).

ing to White (1989:72), misunderstandings between native speakers are far more likely to bring about negative feelings, as they would be attributed to the personalities of the participants, not their linguistic skills. Second, the fact that the register of the conversations was casual may be an important factor in explaining the positive ratings in the questionnaire. A casual register is one in which the participants feel no pressure to communicate. One can speculate how different these results might be if the conversational register were more rigid and/or more demanding as one might find in the workplace or at school. Nonetheless, there was a slight difference in conversational satisfaction between the two cultures.

For all items except for three (items 1, 8, and 9), the British participants' scores seemed to indicate that they were less satisfied with the conversations than their Japanese interlocutors. This was anticipated as the British participants were conversing in their native language, thus it stands to reason that they have a more precise idea of what constitutes conversational satisfaction as it pertains to English. Items 5, 7, and 11 were the only items to produce a salient differential in scores between the two cultures of more than 1 (1.5, 1.88, and 1.12 respectively). In these cases, the British participants felt their interlocutor expressed less interest in the conversation than the Japanese participants did, the British participants felt less encouragement to continue talking than the Japanese participants did, and the British participants perceived their 
interlocutors to be less warm and friendly than the Japanese participants did.

I used the Pearson Product-Moment Correlation Coefficient (PPMC) to correlate the number of Japanese backchannels, and the British speakers' ratings on individual items of the conversational satisfaction questionnaire. The results of this analysis were largely inconclusive. None of the correlation coefficients was found to be statistically significant (at $\mathrm{p}>.05$, two-tailed test). That is, there is no systematic significant relationship between the number of Japanese listeners' backchannels and the British speakers' ratings on the conversational satisfaction inventory. With this in mind, it is also understood that the higher the correlation coefficient between two sets of scores, the more likely they are to be related. Hence, the correlation coefficients regarding items 8 and 15 may at least be considered to be interesting as they produced correlation coefficients noticeably higher than the other items and closer to the critical value, which determines statistical significance (item $8=.50$, item $15=$ .59 , and critical value $=.71$ ). The correlation coefficient regarding these items reveals two trends in the data. First, regarding item 8 , the more frequently the Japanese listeners sent backchannels, the more their British interlocutor perceived them to be impatient. Second, regarding item 15 , the more frequently the Japanese sent backchannels, the more their British interlocutors felt they were being interrupted. While these trends in the data cannot be used to confirm any hypothesis because they are not statistically significant, they can be used to challenge the findings of White (1989).

In her study, White (1989) found that American speakers perceived Japanese listeners who sent backchannels more frequently than other Japanese listeners as a positive trait. More specifically, White (1989) found that the more frequently Japanese sent backchannels, the more Americans perceived them to be showing signs of comprehension, interest, encouragement, and concern. Hence, the trends found in the present study differ from the findings in White (1989), and seem to offer support to the earlier contentions made by Lebra (1976) and Mizutani (1982) that native speakers of English may misunderstand Japanese frequent interjections as interruptions and/or a sign of impatience.

\subsection{Factors affecting participants' behaviour}

Once examined the data produced by the interviews, several interesting themes came to light. These themes involve insights into several areas such as the phenomenon known as the observer's paradox, the possibility that the participants alter their behaviour when interacting across cultures, the mind set of the Japanese participants when using backchan- 
nels, and the British participants' perceptions regarding Japanese EFL speakers' backchannels.

Considering the possibility of the observer's paradox in this study, I asked all participants how they felt about conversing in front of the camera. The majority of participants in my study (all the British participants and six of the eight Japanese participants) indicated that they were not conscious of the camera once the conversation developed. However, in asking participants whether they change how they speak when speaking across cultures, many of the participants indicated that they did. Some of the British participants acknowledged that they probably speak more slowly and are more tolerant of misunderstandings in communication, while some of the Japanese participants admitted to being especially nervous when speaking to foreigners because they do not know how to act.

\subsection{Functions of Japanese backchannels}

When I asked the Japanese participants what the functions of their backchannels were during the playback of their conversations, their responses seemed to indicate that their backchannels were largely determined by the context of the conversation at that time. The most frequently cited responses included showing comprehension, showing agreement, showing empathy, and allowing the other person to continue speaking. However, the last one, allowing the other person to continue speaking, may not be exactly what Schegloff (1982) had in mind when he first described the concept of continuer. In the case of this study, some of the Japanese participants have indicated that they use backchannels as a way to avoid speaking due to shyness, lack of confidence in their English ability, and not knowing what to say. The excerpts below demonstrate this:

Yuki: I often give aizuchi (the Japanese term to describe backchannel) because I feel my English isn't good enough to speak.

Tetsuhisa: Giving aizuchi is much easier than speaking, so I give aizuchi but of course I want to speak to you but my English is not good.

Emi: I think she likes talking more than me so (I) gave aizuchi to let her keep talking.

Toru: I want to say more but I don't (know) what to say so I sometimes just nod.

Masami: I am uncomfortable speaking even in Japanese. I like giving aizuchi because I can join, be a part of the conversation without speaking so much. It's my nature. 
The following excerpts show that some of the Japanese believed they use backchannels often out of habit caused by their occupation:

Etsuko: Because my job is getting customers, I probably use aizuchi more than other Japanese.

Kenji: In my job, patients complain many things, so aizuchi has become my habit. I think when I give aizuchi, they must feel better.

Another reason may be that L2 speakers use backchannels as a way to allow themselves more time to process information. Some of my Japanese participants explain below how they send backchannels to serve this function.

Masahiro: I sometimes say ' $\mathrm{m}$ ' and 'uhum' as a way to give myself time to think so I can think what I want to say next.

Tetsuhisa: In this moment (referring to a misunderstanding in the conversation), in my mind, I was very confused, I thought he said go, but he told me different so I do nodding so he'll continue and I can think what he meant, and then what I want to say.

Taking my analysis one step further, I now explore the potential for misunderstanding and miscommunication caused by ways that the Japanese participants sent backchannels, which might be considered unconventional in English. Some of the Japanese participants' backchannels, which were thought to be unconventional in English, included backchannels such as head nods, uhum, and/or yeah yeah in instances when the Japanese participant disagreed or did not understand what the primary speaker was saying. Some of the Japanese respondents cited politeness as a reason they used backchannels in these instances:

Yuki: I couldn't understand what she said but I did not want to interrupt her because it would be rude.

Tetsuhisa: I didn't understand what he said but I wanted the conversation to continue smoothly and I didn't want to interrupt him.

Toru: $\quad$ Many times I didn't understand half of what he was saying but I gave aizuchi because I wanted him to continue speaking, and I didn't want to interrupt because it is rude.

Emi: $\quad$ I didn't think so, what she said, but I couldn't tell her because I don't want to make her feel bad, so I just give aizuchi so she can talk more.

Masami: I didn't have such a case here, but usually I wouldn't tell someone if I disagree (with) their opinion because I don't 
want to lose nice atmosphere. This is Japanese culture. Do you know omoiyari?

Masahiro: I couldn't show I didn't understand because it's the Japanese mind. If I show, he loses his face, and I too lose my face.

Thus in explaining why the Japanese participants sometimes used backchannels in ways which may be unconventional in English, some of the opinions above seem to support Locastro's $(1987,1999)$ assertion that Japanese culture has a major influence.

In order to understand this, it is necessary to consider the Japanese cultural concept called wa (also called omoiyari) because it is a key concept in understanding Japanese people, and like so many other Japanese cultural concepts it is difficult for westerners to grasp because it has no English equivalent. $W a$ can be described as a cultural concept, which puts great pressure or emphasis on Japanese people to maintain group harmony (Elwood 2001: 12). Relating the Japanese cultural concept of $w a$ to this study, it has been noted by several researchers such as Kenna and Lacey (1994), White (1989), and Locastro (1987, 1999) that Japanese use backchannels primarily as a means of maintaining harmony. Thus, speech acts such as disagreeing and interrupting, which disrupt the flow of a conversation and have the potential of leading to confrontations, may be especially difficult for Japanese to perform. As has been documented elsewhere (Loveday 1982:12; Hill 1990:70; Matsumoto and Boye Lafayette 2000: 193), maintaining harmony and protecting face are much more important virtues than clarity and directness in Japanese culture.

Furthermore, other Japanese respondents stated that they sometimes sent backchannels when they did not understand how to avoid humiliation. This can be seen in the following examples:

Kenji: $\quad$ Sometimes even though I don't understand I do aizuchi. There are two reasons for this. One is I don't want to hurt him (cause him to lose face), and this is more important, um this is the truth, I don't want him to think I'm stupid. I'm afraid he thinks I'm stupid and my English is very poor.

Yuki: I was afraid if she could see I couldn't understand she'd think I'm not clever.

These sentiments give further credence to Locastro's $(1987,1999)$ cultural explanation of Japanese backchannels. As Noguchi (1987:22) affirms, many Japanese have a difficult time showing that they do not know something because of the negative implications in Japanese culture of such conduct. He goes on to explain that, in Japanese culture, I don't 
know $X$ often presupposes that the speaker lacks knowledge of $\mathrm{X}$ because of a lack of intelligence or a lack of interest in X. In contrast, I don't know $X$ in English does not seem to presuppose a lack of intelligence or lack of interest in X, but only a lack of knowledge of X.

\subsection{British participants' perceptions of Japanese EFL speakers' backchannels}

I now explore how the British participants perceived their Japanese interlocutors' backchannels. One of the trends emerging in the data was the perception that the Japanese participants used backchannels to avoid speaking. As we have already touched upon, the fact that the British participants would have to carry the conversation was generally accepted by them as it was their native language. The following excerpts, however, seem to imply that it may have detracted from their enjoyment of the conversation:

Victoria: Her reactions made me feel like she didn't want to speak, be put on the spot as she seemed content to just let me take it (the primary speakership in the conversation) but I get tired after a while ya know.

William: If I didn't ask him direct questions he probably would just continue nodding. I felt as though he didn't really want to speak. Maybe he was nervous.

Elizabeth: Of course I'd love for her to have spoken more, but I don't think it's in her nature to do so. She seems much more comfortable in a listener's role.

Charles: Well in a real life situation, like if I was in a bar or something, I doubt that I'd try so hard to keep the conversation going.

Furthermore, some of the British respondents felt some displeasure in the conversations because they believed their interlocutors were not genuinely listening in some instances. In the following excerpts, the British participants cited that their interlocutors were more concerned with their accuracy of English and how they were being perceived than the actual communication itself.

Charles: It's tough staying focused because he's not paying attention sometimes. See (refers to screen) on the surface, he's conveying that he's still interested, but he's fiddling with his fingers a lot which means he's thinking way ahead of what he's going to say next.

William: He seemed too worried about his English and not enough about what I was saying. 
Another source of confusion and/or minor irritation mentioned by several British participants was when the Japanese participants sent backchannels in situations that might be considered unconventional in English. The following examples demonstrate their feelings:

William: I feel he's nodding out of habit whether he understands or not. Victoria: Honestly I think she's just agreeing with everything I say no matter how she feels which is too bad because I'd like to hear her opinion; it would do heaps to stimulate the conversation.

The following excerpts refer to the British participants' viewpoints in this area based on their general experiences in Japan:

Victor: You have to watch carefully, trip them (Japanese EFL speakers) occasionally with a question, or confirmation check or something, otherwise you won't know if they're really understanding you.

Berenice: In Japan, shopkeepers on the street always nod and act like they understand but they really don't and then we try to buy something and it's like did we miss something?

Charles: I don't know why they (Japanese EFL speakers) just can't give their opinions. You (referring to all people) can disagree without hurting people.

Victoria: The most difficult thing I find in teaching in Japan is that the students never tell you when they don't understand. Lots of times they'll just pretend they understand but then you ask them to do something and they won't have the faintest clue what you mean.

Further, some of the British respondents acknowledged that the lack of variability in the types of backchannels Japanese EFL speakers send is a probable reason for the negative effect on communication. The following statements illustrate this point:

William: Some of his reactions felt unnatural. They weren't diverse enough. I couldn't tell if he really knew what I meant or not.

Margaret: I guess I was looking for a more emphatic expression that time.

Charles: (Speaking generally) Whether it's through lack of English phrases, nothing other than 'm', 'm' comes back, not like 'really' or 'I see'. You've got to have more situation responses in English. For example, if I said I was going to jump off a cliff, I'd like an 'are you crazy' rather than 'm' and a nod.

Victoria: I couldn't really tell if she was listening because all her reactions were similar. There wasn't enough of an expression. 
In mentioning the degree to which the Japanese participants responded in terms of enthusiasm, the British responses seem to have again touched upon the issue of culture. Several studies have shown that quietness and withdrawal are typical of Asian people (Caplan et al. 1991; Townsend and Danling 1998; Trueba 1990).

\subsection{Summary of Results}

In summarizing the findings in this study, I attempt to answer the two research questions: (1) Did the two cultures use backchannels differently in this study, and (2) if there were differences in the backchannel behaviour of the two cultures, how did these differences affect communication? In answer to the first question, this study found that the two cultures used backchannels differently in many areas. With regard to frequency, the Japanese participants used slightly more backchanels per interlocutor word than the British participants. In terms of the variability of the types of backchannels used by each culture, this study found that the British participants' backchannels contained more variability than did the Japanese participants, and there were several differences in verbal items making up these backchannels as they pertain to each culture. Regarding discourse contexts favouring backchannels, I observed that the Japanese participants sent noticeably more backchannels in three discourse contexts: at or directly after a pause, directly after the primary speaker's nonverbal gesture, and directly after the lexical item ya know or a tag question. Further, the Japanese participants acknowledged that they sometimes send backchannels to avoid speaking, to allow interlocutors to continue speaking, to allow themselves additional time to process information, and out of habit.

In answering the second question, this study attempts to determine how the differences between the two cultures' backchannel behavior affected communication. The British participants acknowledged that some of the ways their interlocutors use backchannels (and Japanese EFL speakers generally for that matter) are likely to have a negative effect on intercultural communication. A correlation analysis showed that the more frequently the Japanese participants sent backchannels, the more the British participants felt they were being interrupted, and the more the British participants perceived their interlocutors to be impatient. Some of the irritants they mentioned include the Japanese tendency to use backchannels as a way to avoid speaking, to not focus on the communication because they are worried about their English, and their lack of variability in the types of backchannels they send. Further, they also expressed displeasure with the Japanese tendency to send backchannels when they disagree and/or do not understand. 


\section{Conclusion}

\subsection{Interpretation of the findings}

In my attempt to inform EFL pedagogy in Japan, I now assess the implications of these findings. As I have shown, this study demonstrates that Japanese EFL speakers may use backchannels differently from native English speakers in many respects, and at times these differences may have a negative effect on intercultural communication. Consequently, I feel that these findings support the conclusion that Japanese EFL learners would be better served if backchannels were given a higher priority in EFL teaching in Japan. Having acknowledged this, my next task is to relate our findings to EFL classrooms in Japan.

\subsection{Pedagogical implications}

Prior to developing strategies for teaching Japanese EFL learners how to use backchannels, it is important to consider why they use backchannels in the manner that they do. This study provides some insights, which may assist teachers in this area. The relationship between backchannels and discourse is not a linear one. Rather, it is complex and multifaceted in that several variables such as culture, the negotiating of turn-taking in a conversation, personality, and language ability all play prominent roles. Hence, teachers would be ill-advised to expect students to produce native-like backchannels soon after they are taught.

The findings in this study suggest that Japanese culture plays a large role in how Japanese EFL speakers use backchannels. It seems that the primary function of Japanese backchannels is to maintain harmony, and thus avoid confrontations in conversations. Although this use of backchannels may sometimes contribute to miscommunication in intercultural encounters, EFL teachers would be well served to not push or force their students to use and/or avoid using backchannels in ways which they may feel uncomfortable. According to Alpetkin and Alpetkin (1984: 17), Brumfit (1980:94), and Kramsch (1998: 65), aggressive attempts at making EFL students bicultural are often met with resistance and can result in their disengagement from the target culture. Kramsch (1998: 65) offers insights into the sensitivity of this issue by explaining that people forge their identities and beliefs through their culture, hence any attempts by teachers or anyone else for that matter to change their behaviour in this way may feel like a personal attack. Thus, as far as culture is concerned, I can only advise teachers to be cautious and keep in mind that the degree to which a student wishes to acculturate to the target culture is largely up to her/him. 
Nonetheless, many students are more than willing to embrace the target culture in their efforts to learn English. Thus, I advance that the first step to teaching backchannels is to make learners conscious of how backchannels may be used differently in English. Some of the methods that can be used to achieve this goal include drama, role-play, and video techniques (see Cullen 2000; Murphy and Woo 1998; Nolasco and Arthur 1987). The premise in all three of these activity types is the same in that each activity type involves having learners observe and make note of various types of backchannel behaviour. Teachers can subsequently engage their learners in discussions comparing the backchannel behaviour of people from different cultures, and then allow for practice opportunities. By doing this, teachers can draw attention to various phenomena involving backchannels such as frequency, variability, function, and the discourse contexts favouring backchannels.

Lastly, in dealing with the claim that Japanese often send backchannels as a way to avoid speaking in English, it is necessary to consider the reasons for these actions before any suggestions can be made. In cases where Japanese send backchannels because they are afraid to speak (i.e. shyness), teachers would be well served in not forcing the issue. It may be that learners just need more time in getting acclimatized to the norms of the target culture. As I alluded to above, teachers' aggressive attempts at persuading learners to speak more would probably only exacerbate learners' cultural inhibitions. However, in situations where students would like to speak, but send backchannels because they do not understand or do not know what to say, teachers can certainly assist these students. One of the ways they can do this is to help learners develop conversational repair strategies in these situations such as how to say you do not understand, how to interrupt, disagreeing, etc. (see Dornyei and Thurrell 1994 for an extensive list).

In conclusion, this study has served to highlight the importance of backchannels in intercultural communication, and has provided several insights explaining why Japanese EFL learners use backchannels the way they do. Unquestionably, there is a cultural element that we know very little about, and thus I believe the first step in bringing about more fruitful intercultural encounters with Japanese EFL speakers is to make a sincere and concerted effort to learn more about their culture. It is my hope that these findings will be successful in informing EFL teachers and drawing research attention to this area. If the conclusion that backchannels warrant more attention in EFL classes in Japan is accepted, then the next step in terms of research attention in this area may be a closer look at how Japanese EFL learners best acquire this seemingly elusive aspect of sociolinguistic competence.

Siebold University of Nagasaki 


\section{References}

Alptekin, C. and M. Alptekin (1984). The question of culture: EFL teaching in nonEFL speaking countries. ELT Journal 38(1), 14-20.

Auer, P. (1996). On the prosody and syntax of turn-continuations. In Couper-Kuhlen, E. and M. Selting (eds.), Prosody in Conversation. Cambridge: Cambridge University Press, $57-100$.

Barnlund, D. (1974). The public self and the private self in Japan and the United States. In Condon, G. and M. Sato (eds.), Intercultural Encounters with Japan. Tokyo: Simul Press, 27-96.

Brown, J. (2001). Using Surveys in Language Programs. Cambridge: Cambridge University Press.

Brumfit, C. (1980). Problems and Principles in Language Teaching. Oxford:Pergamon Press.

Caplan, N., M. Choy, and J. Whitmore (1991). Children of the Boat People: A Study of Educational Success. Ann Arbor: University of Michigan Press.

Capper, S. (2000). Nonverbal communication and the second language learner: Some pedagogical considerations. The Language Teacher 24(5) (online). Available: http:// langue.hyper.chubu.ac.jp/jalt/pub/tlt/00/may/capper.html

Clancy, P. (1982). Written and spoken style in Japanese narratives. In Tannen, D. (ed.), Spoken and Written Language: Exploring Orality and Literacy. Norwood: Ablex. Tannen, 55-76.

Clancy, P., S. Thomson, R. Suzuki, and H. Tao (1996). The conversational use of reactive tokens in English, Japanese and Mandarin. Journal of Pragmatics 26(1), $355-387$.

Cullen, B. (2000). Practical techniques for teaching culture in the EFL classroom. The Internet TESL Journal 6(12) (online). Available: http://www.aitech.ac.jp/'iteslj/ techniques/Cullen-Culture.html

Dornyei, Z. and S. Thurrell (1994). Teaching conversation skills intensively: course content and rationale. ELT Journal 48(1), 40-49.

Duncan, S. (1974). On the structure of speaker-auditor interaction during speaking turns. Language in Society 2(1), 161-180.

Duncan, S. and D. Fiske (1977). Face-to Face Interaction: Research, Methods, and Theory. Hillsdale: Erlbaum.

Elwood, K. (2001). Getting Along with the Japanese. Tokyo: Ask.

Erickson, F. (1979). Talking down: Some cultural sources of miscommunication in interracial interviews. In Wolfgang, A., (ed.), Nonverbal Behavior: Applications and Cultural Implications. New York: Academic Press, 99-126.

Fries, C. (1952). The Structure of English. New York: Harcourt Brace.

Goodwin, C. (1981). Conversational Organization: Interaction between Speakers and Hearers. New York: Academic Press.

- (1986). Between and within: Alternative sequential treatment of continuers and assessments. Human Studies 9(1), 205-217.

Hall, E. (1974). Handbook for Proxemic Research. Washington: Society for the Anthropology of Visual Communication.

Hecht, M. (1978). The conceptualization and measurement of interpersonal communication satisfaction. Human Communication Research 4(3), 253-264.

Hill, T. (1990). Sociolinguistic aspects of communicative competence and the Japanese learner. Dokkyo University Studies in English 36(1), 69-104.

Johnstone, B. (2000). Qualitative Methods in Sociolinguistics. New York: Oxford University Press.

Kendon, A. (1967). Some functions of gaze-direction in social interaction. Acta Psychologica 26(1), 22-63. 
- (1977). Some functions of gaze-direction in two-person conversation. In Kendon, A. (ed.), Studies in the Behavior of Social Interaction. Bloomington: Indiana University Press, $13-51$.

Kenna, P. and S. Lacy (1994). Business Japan: A Practical Guide to Understanding Japanese Business Culture. Lincolnwood: Passport Books.

Kramsch, C. (1998). Language and Culture. Oxford: Oxford University Press.

Labov, W. (1972). Sociolinguistic Patterns. Philadelphia: University of Pennsylvania Press.

Lebra, T. (1976). Japanese Patterns of Behavior. Honolulu: The University of Hawaii Press.

Locastro, V. (1987). Aizuchi: A Japanese conversational routine. In Smith, L. (ed.), Discourse Across Cultures: Strategies in World Englishes. London: Prentice Hall, $101-113$.

- (1999). A sociocultural functional analysis of fragmentation in Japanese. Multilingua. $18(4), 369-389$.

Loveday, L. (1982). The Sociolinguistics of Learning and Using a Non-native Language. Oxford: Pergamon.

Lustig, M. and J. Koester (1993). Intercultural Competence: Interpersonal Communication Across Cultures. New York: Harper Collins.

Markel, N. (1975). Coverbal behavior associated with conversation turns. In Kendon, A., R. Harris, and M. R. Key (eds.), Organization of Behavior in Face-to-Face Interaction. The Hague: Mouton, 189-197.

Matsumoto, M. and D. Boye Lafayette (2000). Japanese Nuance in Plain English. Tokyo: Kodansha.

Maynard, S. (1986). On back-channel behavior in Japanese and English casual conversation. Linguistics 24(6), 73-105.

- (1987). Interactional functions of a nonverbal sign: Head movement in Japanese dyadic conversation. Journal of Pragmatics 11(1), 589-606.

- (1989). Japanese Conversation Self-Contextualization Through Structure and Interactional Management: Self-Contextualization Through Structure Interaction. Advances in Discourse Processes, Vol. 35. Norwood: Ablex.

- (1990). Conversation management in contrast: Listener responses in Japanese and American English. Journal of Pragmatics 14(1), 397-412.

- (1997). Analyzing interactional management in native/non-native English conversation. IRAL 35(1), 37-60.

Miller, L. (1988). Listening behavior in conversations between Japanese and Americans. In Blommaert, J. and J. Verschueren (eds.), Intercultural and International Communication. Amsterdam: Benjamins, 111-130.

Mizutani, N. (1982). The listener's responses in Japanese conversation. Sociolinguistic News-letter 13(1), 33-38.

- (1983). Aizuchi to ootoo. In Mizutani, O. (ed.), Hanashi Kotoba no Hyoogen. Tokyo: Chikuma Shoboo. 37-44.

Murphy, Y. and L. Woo (1998). Video conversation for student evaluation: Educational video's diamond in the rough. The Language Teacher 22(8) (online). Available: http://langue.hyper.chubu.ac.jp/jalt/pub/tlt/98/aug/woo.html

Noguchi, R. (1987). The dynamics of rule conflict in English and Japanese conversations. IRAL 25(1), 15-24.

Nolasco, R. and L. Arthur (1987). Conversation. Oxford: Oxford University Press.

Okushi, Y. (1990). Misunderstood efforts and missed opportunities: An examination of EFL in Japan. Penn Working Papers in Educational Linguistics 6(2), 65-75.

Oreström, B. (1983). Turn-Taking in English Conversation. Lund: Lund University Press. 
Phillips, S. (1976). Some sources of cultural variability in the regulation of talk. Language in Society 5(1), 81-95.

Sacks, H., E. Schegloff, and G. Jeffesron (1974). A simple systematics in the organization of turn-taking for conversation. Language 50(1), 696-735.

Sapir, E. (1929). The status of linguistics as a science. Language 5(1), 207-214.

Schegloff, E. (1982). Discourse as an interactional achievement: Some uses of "UHHUH" and other things that come between sentences. In Tannen, D. (ed.), Georgetown University Roundtable on Language and Linguistics, Analyzing Discourse: Text and Talk. Washington: Georgetown University Press, 71-93.

Tannen, D. (1984). Conversational Style: Analyzing Talk Among Friends. Norwood: Ablex.

Tao, H. and S. Thompson (1991). English backchannels in Mandarin conversation: A case study of superstratum pragmatic inference. Journal of Pragmatics 16(1), $209-223$.

The Japan Times (1983). Japanese mannerism is a key point in IBM case. January $29,2$.

Tottie, G. (1990). Conversational Style in British and American English: The Case of Backchannels. Mimeo: University of Uppsala.

Townsend, J. and F. Danling (1998). Quiet students across cultures and contexts. English Education 31(1), 4-25.

Trueba, H. (1990). The role of culture in literacy acquisition: An interdisciplinary approach to qualitative research. Qualitative Studies in Education 3(1), 27-42.

Vygotsky, L. (1962). Thought and Language. Cambridge: The M.I.T. Press.

White, S. (1989). Backchannels across cultures: A study of Americans and Japanese. Language in Society 18(1), 59-76.

Yamada, H. (1990). Topic management and turn distribution in business meetings: Americans versus Japanese strategies. An Interdisciplinarian Journal for the Study of Discourse 10(3), 271-275.

Yngve, V. (1970). On getting a word in edgewise. Chicago Linguistic Society 6(1), $567-578$.

Zimbardo, P. (1977). Shyness: What it is - What to Do About it. Reading: Wesley. 